\title{
The clinical assessment of acts of violence: mental mechanisms and subjectivity
}

\author{
Rajan Nathan (1) \& Peter Wilson
}

\begin{abstract}
SUMMARY
Approaches to assessing violence in clinical practice have been influenced by developments in the field of risk assessment. As a result, there has been a focus on identifying and describing factors associated with violence. However, a factor-based approach to assessing violence in individual cases has limited clinical utility. In response, the benefits of a formulation-based approach have been promoted. This approach is enhanced by an understanding of the specific mental mechanisms that increase the likelihood of violence in the individual case. Although there is an empirical evidence base for mental mechanisms associated with violence, this literature has not been distilled and synthesised in a way that informs routine clinical practice. In this article the authors present the key mechanisms that are known to be associated with violence in a way that is relevant to the clinical assessment of violence and, in turn, can inform clinical and risk management.
\end{abstract}

\section{LEARNING OBJECTIVES}

After reading this article you will be able to:

- recognise the key elements of the violent mental state

- apply a framework for assessing and understanding the subjectivity of the commission of violent acts

- understand the importance of the careful use of explanatory constructs in the assessment of violence.

\section{DECLARATION OF INTEREST}

None.

\section{KEYWORDS}

Violence; formulation; subjectivity; explanatory models; mechanisms.

Most patients with mental disorder are not violent, but on the rare occasions when violence occurs we should attempt to understand it. As clinicians, whether we set out to understand the patient at the level of symptoms, diagnoses or formulation, the primary medium through which we achieve understanding is patients' subjective experiences. By extension, our understanding of a person's actions is limited unless we explore their inner world in relation to those actions. This article presents an overview of the evidence on the inner world of an individual at the time he or she carries out a violent act. It aims to assist clinicians who endeavour to develop an understanding of a person's history of acts of violence in a way that informs clinical, and risk, assessment and management. Specific attention is given to the proximal processes present around the time of the violent act.

We use the terms violence and aggression in this article to refer to 'a range of behaviours and actions that can result in harm, hurt or injury to another person' (National Collaborating Centre for Mental Health 2015: p. 19). The particular focus is on physical behaviours that can cause physical harm.

\section{Explanatory concepts}

Narrative descriptions of violence often rely on terms that convey explanatory meaning about the aggressor's mind. Such concepts include cause, reason, intention, motivation, function, rationalisation and justification. Some of these terms are used interchangeably and their meaning is not always clear from the way they are used. Being clear about the way terms are used (a) demonstrates the different frames of reference that can be adopted when attempting to understand the subjective perspective of an aggressive actor, (b) in so doing, provides a helpful back-drop to the assessment of the subjective perspective of aggression (including the approach presented below), and (c) encourages the careful use of language in describing the patient's mental world. The way in which we propose that explanatory terms are used (summarised in Box 1) is not determinative for all purposes because these terms can legitimately be used in different ways. The key point, however, is to encourage the careful and explicit use of such terms in the process of assessment and formulation, and particularly in how the outcome of these clinical activities is documented.
Rajan Nathan, MBBCh, MMedSc MRCPsych, DipFSc, MD, is a consultant forensic psychiatrist and director of research and effectiveness with Cheshire Wirral Partnership NHS Foundation Trust, an Honorary Senior Research Fellow at the University of Liverpool, a Visiting Professor at the University of Chester, and an Adjunct Professor at Liverpoo John Moores University, UK. He has worked in a wide range of clinical settings, including secure hospitals, prisons and the community. Since undertaking his doctoral research on the developmental pathways to serious violence, he has retained an academic and clinical interest in understanding violence. Peter Wilson, BA Law, MBBS, MRCOG, MRCPsych, is a trainee psychiatrist with Health Education North West and is currently working at Cheshire and Wirral Partnership NHS Foundation Trust, UK. His academic interests include the phenomenology and psychopathology of psychosis, and the brain and mind process mechanisms that underly it. Correspondence Rajan Nathan. Email: taj.nathan@nhs.net

First received 13 Aug 2019 Final revision 9 Nov 2019 Accepted 19 Nov 2019

\section{Copyright and usage} (c) The Authors 2019

A podcast is available for this article at: https://soundcloud.com/bjpsych/ bja-2019-75. 
B0X 1 Formulation-based framework for the use of explanatory constructs in relation to violent behaviour

Cause: That which brings about the violent act

Reason: That for which the violent act is brought about

Intention: The objective of the violent act anticipated by the actor

Motivation: Internal state that the violent act was aimed at achieving, based on immediate psychological processes
Function: Internal state that the violent act was aimed at achieving, based on both immediate and wider psychological processes and on interpretive assumptions

Rationalisation: Retrospectively stated reason for, or cause of, the violent act consistent with an accepted form of logic Justification: Type of rationalisation invoking a just reason or cause

\section{Cause and reason}

An 'explanation' may be defined as 'a thing which explains, makes clear, or accounts for something' (Oxford English Dictionary 2019). This broad definition encompasses the more specific types of explanation below. The distinction between cause and reason has been extensively debated. According to Buss (1978) 'causes are that which bring about change' and 'reasons are that for which change was brought about'. Thus, an insulting comment can be the cause of an act of aggression, for which the reason was to retaliate. Buss's definitions are accepted for the framework presented in this article, but although Buss's categorisation implies mutual exclusivity, it needs to be recognised that the distinction can be very fine. For example, the desire to obtain someone else's material possession to fund a drug habit may be both a reason for, and a cause of, a street robbery. However, whereas the desire may be sufficient in itself as a reason, it will form only part of the causal explanation. If the offender was intoxicated, then the disinhibiting effects of the intoxicant may be another part of the causal explanation. Applying Dennett's typology of explanation, reasons answer 'What for?' questions (Dennett 2017). According to Dennett, causes, on the other hand, answer 'How come?' questions and are best described in terms of a process narrative. A process narrative is particularly useful when developing an explanatory formulation.

\section{Intention, motivation and function}

Motivation and intention can have narrower meanings than reason. Obtaining a material possession that belonged to someone else as an explanation for an act of aggression in the course of a street robbery is a particular sort of reason for which the term 'intention' is used. Intention may be defined as referring to the thing consciously intended, 'that which is intended or purposed' (Oxford English Dictionary 2019). Not all reasons that represent

the actor's mind are intentions. For example, explaining reactive violence in terms of an explosive outburst of anger relies on a mind-based explanation which is not an intention. The cause is the anger and a plausible reason is to express that anger, but this may not have been the conscious objective.

The ordinary use of motivation does not distinguish it from reason, but in the hands of psychiatrists and psychologists the term is used to describe a change in physiological or psychological conditions that behaviour is aimed at achieving (Peters 1960). It can be seen as a driving force for the action. Motivation used in this way emphasises an internal objective that can be distinguished from intention, which tends to refer to an observable objective (e.g. behaviour or environmental event). Applying this type of distinction would lead one to conclude that the intention of the street robbery was to obtain the item, whereas the motivation was to satisfy a desire to achieve a state of mind associated with drug use, which will become possible by selling the stolen item. Bearing in mind this distinction in the assessment of violent acts facilitates the identification of the mental processes. This can be further illustrated by considering the scenario of an intoxicated pub patron impulsively lashing out at another customer who had made a mocking comment. The aggressor reported that his intention was to shut the other man up. Further exploration uncovered that he was motivated by wanting both to reduce his sense of humiliation and to avoid a loss of perceived standing among his peers, who were witness to the interaction. In another example the intention of an aggressive rapist was to commit a rape, whereas he was motivated by a wish to enhance his anticipated sexual arousal with the feelings he would experience when directly witnessing signs that his victim was fearful of him.

As with motivation, the term function is used to describe an internal state-based objective of the act. Whereas motivation is more commonly used to describe proximal processes, function tends to draw on wider psychological processes and involves interpretive assumptions (Hofmann 2017). For example, in the reactive aggression pub scenario mentioned above, the motivation was to reduce feelings of humiliation and avoid perceived loss of status. The function was to counter a worsening of pervasive underlying self-devaluative feelings by providing the aggressor with positive feelings associated with expectations about the way his peers will view him.

\section{Rationalisation and justification}

The term rationalisation is often used to describe a potentially logical, but not necessarily valid, reason for an action offered by the actor after the act has 
occurred. Justification is a particular type of rationalisation that introduces a moral element into the explanation, i.e. relying on a judgement that the reason for the action was at some level a good or a just one. In these senses, rationalisations and justifications offered by the subject of the assessment may interfere with the assessor's attempts to reach an informed and balanced explanation, and they are therefore processes of which the clinician needs to be aware. Although minimisation (or, in its extreme form, denial) may go along with justification, it is not a type of explanation in itself. Rather, it is the assessor's judgement about the discrepancy between the perpetrator's account and the account suggested by independent observers.

\section{Explanatory models of aggression}

On the basis of the empirical literature, researchers have developed explanatory models of the psychological correlates of action in general (e.g. Lerner et al 2015; Ridderinkhof 2017) and violence in particular (e.g. Crick 1996; Anderson 2002; Finkel 2018; Huesmann 2018). Drawing on aspects of these models that are relevant to the clinical assessment, the violent act can be disaggregated into the following elements: (a) trigger, (b) attention, (c) meaning, (d) preparedness, (e) evaluation, (f) inhibition/activation and (g) action. The reality of subjective experience is that there are not defined episodes with clear boundaries separating them from other episodes of experience. However, for practical assessment purposes it can be helpful to conceptualise key snapshots of experience. Our use of the term 'action' in the list of elements above refers to just behaviour and therefore it is not included in the mental state elements below.

\section{Elements of the violent mental state}

\section{Trigger}

Perpetrator accounts of aggressive incidents often begin with a description of something that provokes a change in the individual's mind in a way that leads to the aggression. This may be an environmental event (e.g. an action by another person) and, depending on the model or context, is referred to as a stimulus, cue, trigger, aversive event or provocation. From a subjective standpoint the aggressive episode actually starts with the attention to the event and then the attribution of meaning to it (discussed below). However, the objective properties of environmental events need to be taken into account (Finkel 2018). Although the aggressor may refer to a single event, there is often a series of proximal events that have a similar effect on them.

Internal events may trigger an aggressive state of mind. In the case of post-traumatic stress disorder associated with violence, a re-experiencing phenomenon (e.g. memory or flashback) can lead to a change in subjective experience so that aggression is more likely (Silva 2001). Command auditory hallucinations encouraging violence or persecutory delusions associated with hostility or feelings of imminent threat are other examples of internal triggers (Lamsma 2015). Whether the identified trigger is an environmental event, a memory or a psychotic experience, it is the change in the perpetrator's affect state that is critical in influencing the likelihood of an aggressive response (discussed further below). In some cases, the affect change can occur spontaneously. For example, affective instability in borderline personality disorder involves a sudden and dramatic switch to a negative affect state and in some individuals this state is associated with aggressive urges.

\section{Attention}

Where an aggressive state of mind is triggered by an event, the subjective phase starts with attention to the event. Attention to potential triggers varies both between individuals (Chan 2010) and within the same individual depending on other contextual factors (Banks 2018). Studies of the role of attention in the mental processes leading to aggression tend to focus on events that the aggressor reacts against, i.e. threat-related stimuli (Salum 2016). However, some situations activate attention in a way that leads to aggression because they represent opportunities. For example, a lone female in a secluded area may attract the attention of an individual with sexually sadistic urges, or a shop empty of customers may be of interest to a person seeking an opportunity to commit an armed robbery. These situations may also be deliberately sought out with a view to carrying out the aggressive act. In these scenarios, there may have been an existing preparedness for the use of violence, but the resistance offered by a victim may provoke an angry aggressive reaction. The resistance serves as a trigger for reactive violence for which there had been instrumental preparation, illustrating the overlap between reactive and instrumental constructs.

\section{Meaning}

An event has the potential to become a trigger on account of the meaning ascribed to it. Such events may include the actions of others, such as the adoption of a threatening posture or the utterance of a verbal insult. However, some aggression-prone individuals may attribute threatening meaning to postures or comments that most would not consider threatening, particularly if there is some ambiguity of intent. A tendency to attribute hostile intent to the actions of another is associated with the likelihood of aggression (Dodge 2015; Martinelli 2018). 
As well as threat, other types of meaning that may be attributed to actions so as to trigger violence include challenge, rejection, abandonment, criticism, subjugation, disrespect, humiliation and injustice. The tendency to attribute malign intent is a feature of paranoia. Beliefs about the malign intent of others in paranoid psychosis do not always require a trigger event. In paranoid personality disorder, there is usually an occurrence that has led to the attribution of paranoid meaning. The tendency to persistently bear grudges may lead to considerable delay between the identified event and the violent act. More fleeting paranoid reactions to the actions of others are a feature of borderline personality disorder.

It is possible for an aggressive state of mind to develop in response to an action without the attribution of a particular intent to the victim. As already noted, an affect change without a clear environmental trigger may lead to aggression. Further, a potential aggressor may experience frustration and anger in response to an incident that is unrelated to the victim but then the anger is expressed in the form of aggression towards the victim.

Quantitative studies of the psychological correlates of aggressive acts understandably rely on variables representing aspects of the aggressor's mind. A framework based on these variables does not do justice to the interactive nature of an aggressive encounter. This can be illustrated by the case of a patient who appeared hypervigilant to signs of malign intent and complained that people he met were more reserved or unfriendly with him from the outset than they were with others. Observations revealed that he approached new interactions in a way that the other party in the interaction found abrupt and aloof. When a detailed subjective account was taken, it became clear (to the assessor and the patient) that his default stance was one that was likely to be interpreted as defensive, which in turn would provoke others to amend their interactional style in a way that he found unfriendly. It was recognised that there had been a positive feedback loop in which he had relied on his experience of how people interacted with him as evidence to support his view that it was safer to assume that the world was unjust and that he should be suspicious of others.

\section{Preparedness}

Neurobiological studies (e.g. Repple 2017) have found evidence for one pattern of neural activation that appears to represent a state of preparedness for aggression and another distinct pattern that is thought to represent a top-down regulatory process. The state of preparedness is considered to be equivalent to the subjective experience of an impulse or urge. The regulatory processes can deactivate the impulse, which may be experienced as an urge being resisted.

The likelihood that an aggressive impulse will arise in response to an event ascribed with meaning will depend on a number of factors. Social information processing models of aggression refer to scripts, which have been defined as 'templates that provide a description of events and mental rules to guide behaviour in particular situations' (Gilbert 2017). Aggression is more likely if aggressive scripts are readily available. This depends in part on immediate factors. Attributing hostility, the presence of a weapon or exposure to media violence increases the availability of aggressive scripts (Allen 2018; Huesmann 2018). Wider factors also play a part. A tendency to generate aggressive scripts may have developed in the context of adverse early life experiences and/or antisocial peer-group influences (Huesmann 2016). A general tendency to ruminate can facilitate script rehearsal, as can certain types of psychopathology. Autism spectrum disorder is characterised by a restricted and repetitive pattern of thinking, which in some rare cases may include thinking with a violent content. The bizarre fantasies and preoccupations that are a diagnostic feature of schizotypal personality disorder, and psychotic symptoms in psychotic disorders, are sometimes repetitively replayed in the patient's mind. If the content is violent, there is a potential for aggressive scripts being readily available. By definition, sexual sadistic disorder is manifest in fantasies, urges and behaviour related to the suffering of others.

The process of script availability is conceptually linked to the notion of normative beliefs (Yang 2012; Huesmann 2018). A normative belief that aggression is an acceptable means of resolving conflict will increase the likelihood of an aggressive action impulse in response to a relevant stimulus. The shaping of normative beliefs occurs particularly in the context of significant relationships in the developmental period (Botelho 2016) and through peer influences. The latter influences are powerful in membership of violent gangs, in which the potential for violence is both promoted and a requirement for continued membership (Wood 2014). In-group versus out-group biases, which can facilitate aggressive impulses to members of an out-group (Bohm 2016), are exaggerated in gang culture (Vasquez 2015). However, they can also be activated in other contexts, such as in the presence of racial biases (Mekawi 2016). Normative beliefs, in turn, are related to the notion of sense of identity. Clinical experience suggests that some individuals whose sense of identity and agency relies heavily on their potential for aggression (e.g. to counter 
general feelings of self-devaluation and lack of agency secondary to the effects of previous adversity) are more likely to generate aggressive responses in aversive environmental and/or affect conditions.

The choice of action in a particular situation will depend on not just the type, but also the range of options available. A maladaptive response is more likely if adaptive options are not easily generated (Blair 2016). Thus, the chances of an aggressive impulse being activated is greater if an aggressionprone individual has poor social problem-solving difficulties, since alternative prosocial scripts are less readily available.

In scenarios in which violence is associated with auditory hallucinations, the association is sometimes explained by the content of the voices appearing, from a subjective perspective, to encourage aggression (e.g. command hallucinations), thus provoking an aggressive action impulse.

\section{Evaluation and inhibition/activation}

The likelihood of one particular action impulse being chosen above the others depends on an evaluation of the anticipated consequences of the action (Lerner 2015). Negatively evaluated action impulses will tend to be inhibited. For most action impulses, including many instances of violence, inhibition occurs with very little or no deliberate reflection. Dampening of inhibitory processes that counter action impulses leads to impulsivity. Psychiatric conditions associated with a general attenuation of these processes include attention-deficit hyperactivity disorder (ADHD) and executive dysfunction. If an individual with such a condition is liable to aggressive action impulses then, as with other action impulses, there is an increased risk of translation into action owing to the non-specific effect of reduced action impulse inhibition (Blader 2018). Violence in the context of acute psychosis is sometimes linked to the patient's experience of the control of their actions being overridden, often by external forces (Link 1994).

There are inhibitory processes that are more specific to violence. The normal developmental trajectory involves a peak prevalence of aggression at around 2-3 years of age (Tremblay 2004). A key process accounting for the subsequent reduction in the frequency of aggression is the development of the capacity to implicitly adopt the anticipated perspective of the victim of a future aggressive action (Decety 2018). As a consequence, aggressive action impulses are normatively inhibited by the aversive feelings associated with adopting the anticipated perspective of a suffering victim of violence.

This type of inhibitory effect is attenuated if there is an impairment of the general capacity to readily perspective-take, such as in autism spectrum disorder (Chen 2018). In psychopathy, there is a more specific disturbance in relation to certain emotional states of others, such as fearfulness and disgust (Igoumenou 2017). If this disturbance is enduring, as in psychopathy, then more deliberate planning involving explicit focus on the effects of aggression is not inhibited. The related, but more dynamic, process of moral disengagement has been used to describe how distancing oneself from accepted moral standards can attenuate processes that would otherwise inhibit aggression (Moore 2015). Moral disengagement consequent on extremist ideological indoctrination has been identified in acts of terrorist violence (Bandura 1999). A temporary reduction in emotional perspective-taking associated with dissociation under stress is part of the explanation for some aggressive outbursts by people with borderline personality disorder (Falk 2015). As with ADHD, it is not that individuals meeting the criteria for these conditions necessarily experience greater levels of aggressive action impulses. Rather, in the event of such impulses, the individual's capacity to inhibit the impulse may be attenuated.

\section{Contextual factors}

\section{Emotional processes}

The role of emotional processes throughout this sequence has been increasingly recognised (e.g. Lemerise 2000). In the moment, the goal of an action is the achievement of a preferred emotional state (Lerner 2015). This may be more obvious in the case of violence that is classified as reactive, where the action can be seen as a means to shift from an aversive state to one that is anticipated to be more favourable. Emotional dysregulation is associated with an increased risk of aggression. The relevance of the affect state to violence is not just a feature of its valence (e.g. negative or aversive) or stability, but also its type. There is a particular association between anger and aggression (Wyckoff 2016). The way attention is allocated and the way stimuli are understood is dependent on the individual's emotional state at the time. For instance, anger and irritability increase the likelihood of attention bias to threat-related cues (Salum 2016) and of the misinterpretation of cues (Li 2016). Other negative emotions, such as fear, are associated with aggression in some circumstances (Roberton 2012).

Aversive conditions that are associated with an increased likelihood of aggression include pain, stress and heat (Groves 2018). However, an aversive state is not always a necessary baseline condition. The role of excitement or arousal-seeking has been 
linked with aggressive behaviour in antisocial and dissocial personality disorders (Howard 2011). Instrumental aggression can also be explained as a way of reaching a predicted preferred affect state (e.g. from a baseline state to the anticipated affect state associated with illegally acquiring an item of value; or the use of domestic violence in the context of a wider coercive dynamic to reach an affect state associated with dominance and control). The intensity of the affect associated with the meaning ascribed to a stimulus can be influenced by contextual factors. Thus, the experience of being challenged or humiliated is likely to be heightened by the presence and reaction of onlookers (Mann 2017). This context may also lead to an aggressive action impulse being favoured since it is associated with an anticipated status boost and/or an avoidance of status loss in comparison with the anticipated outcomes of a non-aggressive response (Anderson 2015). This may in part be dependent on the individual's perception about the onlookers' beliefs and attitudes.

\section{Substance use}

Empirical studies have found a robust relationship between violence and the use of alcohol and drugs (Duke 2018). Much of the research into the mechanisms that may account for this association has focused on the effects of alcohol. The pharmacological effects that increase the likelihood of violence include (a) narrowing of attention (which for aggression-prone individuals may lead to a narrowing of attention on a stimulus perceived as provoking), (b) reduction in the capacity to generate a range of potential responses to the perceived provocation (resulting in a temporary state akin to poor problem-solving), (c) an intensification of the affect state (which may increase the likelihood of aggression if the affect state is anger or fear) and (d) reduction in the power of inhibitory influences (such as implicit perspective-taking or explicit consequences of antisocial behaviour) (Graham 2000; Parrott 2018; George 2019). Social factors that may also contribute to the association between violence and substance use include the circumstances in which the substance is obtained (e.g. engagement in antisocial behaviour with antisocial peers) and consumed (e.g. where groups of people are in confined spaces and in-group/out-group dynamics are more prevalent) (Perdersen 2016).

\section{Illustrative case vignettes}

The three fictitious vignettes below illustrate the way (a) explanatory constructs can be used and (b) the subjectivity of violent mental states (Box 2) can be disaggregated in the context of different types of violence. Function is not included since the definition of function in this model requires account to be taken of a broader psychological profile than is offered in these brief vignettes. The particular use of explanatory constructs and the mental state elements presented in Boxes 3-5 are specific to these cases and cannot be generalised to violent acts of a similar type. The approach advocated involves developing an understanding of the violent act from an evaluation of the perpetrator's unique subjectivity.

\section{Sexual violence vignette}

A is a 25-year-old male who, in the early hours of the morning, was walking home from a night out with his friends when he saw an adult female ahead of him walking alone. He caught up with the woman and physically assaulted and attempted to rape her. He fled when he heard calls from a window overlooking the alley where the offence took place. On assessment, he admitted to a history of voyeurism, but he did not have any previous convictions. He disclosed that since his teenage years his level of sexual arousal had been enhanced by images of him engaging in aggressive sexual acts with nonconsenting post-pubescent females. He reported that he had not planned the offence and the point at which he definitely knew he was going to commit the offence was shortly after seeing the victim. However, he said that earlier that evening he had fallen out with his friends and he recognised that, when frustrated for any reason, he was more

BOX 2 Elements of the violent mental state

Trigger: ${ }^{a} \quad$ Internal or external event that provokes an appreciable mental state change that leads to a violent act

Attention: Awareness of the trigger

Meaning: The meaning attributed to the trigger so as to make a violent act more or less likely

Preparedness: A state of mental readiness to respond to the trigger
Evaluation: The value applied to the anticipated outcome of the prepared for response

Inhibition/activation: Inhibition or activation of the prepared for response

Action: The violent act

a. An external event that triggers a violent mental state can be described independently of the aggressor's mental state. 


\section{BOX 3 Subjectivity in perpetration of sexual violence by $A$}

\section{Explanatory constructs}

Cause: Violent sexual urge

Reason: To dominate and sexually aggress

Intention: To rape the victim

Motivation: To achieve a heightened state of emotional and sexual arousal associated with coercive sexually aggressive dominance of the victim

Mental state elements

Attention/trigger: Seeing the lone woman

Meaning: Believing that the situation represented an opportunity to act on his sexual fantasy
Preparedness: Urge to commit the violent sexual attack

Evaluation: Positive evaluation of urge associated with anticipated enhancement of emotional/sexual experience and release of stress feelings

Inhibition/activation: Activation of urge by the belief that he would be able to commit the offence and escape the scene undetected; and attenuated inhibitions due to narrowing of focus on own interests and away from the perspective of others

Emotional context: Excitement in current situation and lingering feelings of frustration from earlier events

\section{BOX 4 Subjectivity in perpetration of psychotic violence by B}

\section{Explanatory constructs}

Cause: Aggressive urge in response to his misinterpretation of the victim's actions as hostile

Reason: To prevent the man stopping him leaving the toilets

Intention: To get away

Motivation: To reduce the fear of imminent attack and express anger at his perceived situation

\section{Mental state elements}

Attention/trigger: Noticing the man standing outside the toilet cubicle
Meaning: Believing that this man was part of a network of persecutors and was going to stop him escaping from them Preparedness: Urge to hit the man

Evaluation: Positive evaluation of urge due to anticipated means of (a) escape from a dangerous situation and (b) expressing built-up frustration Inhibition/activation: Reduced inhibitions due to his belief that this man was about to attack him and activation of urge due to encouraging voices

Emotional context: Fear for his safety and anger about how he believed he was being treated more generally likely to seek out aggressive sexual pornography. A's subjectivity is evaluated in Box 3 .

\section{Psychotic violence vignette}

$\mathrm{B}$ is a 23-year-old man who was transferred to hospital from police custody under section 2 of the Mental Health Act 1983. He had been taken into custody after being arrested for an assault on another man at a railway station. During the inpatient assessment, B was deemed to be suffering from a psychotic illness. Several months before his admission, he had developed a belief that he had been placed under surveillance in his flat by neighbours whom he thought were working for the

BOX 5 Subjectivity in perpetration of violent robbery by C

\section{Explanatory constructs}

Cause: Angry response to being prevented from leaving with the stolen money

Reason: To be able to escape with the stolen money

Intention: To get away with the stolen money

Motivation: To express anger, to reduce feelings of entrapment, and to achieve feelings of relief and excitement associated with escaping with the stolen money

\section{Mental state elements}

Attention/trigger: A man preventing

him from leaving the shop

Meaning: Inability to escape the scene and to keep the money to buy drugs

Preparedness: Urge to use violence with a weapon
Evaluation: Positive evaluation of urge associated with the anticipation of escaping with the money to buy drugs Inhibition/activation: Reduced inhibitions due to effects of cocaine and activation of urge due to angry feelings Emotional context: Anger at being stopped; excitement about escaping with means to obtain drugs; and anxiety about the prospect of experiencing withdrawal symptoms 
MCO answers

$1 \mathrm{~d} \quad 2 \mathrm{~d} \quad 3$ e 4 a $5 \mathrm{c}$ government. Later his beliefs became more generalised in that he thought the surveillance was continuing wherever he went and that he was about to be abducted and tortured. He also experienced voices warning him to be careful about people as he passed them in the street. Sometimes the voices would encourage him to attack his persecutors, although he did not want to. On the day of his arrest, he had become so overwhelmed by his experiences that he decided to leave the area and travel by train to London. As he came out of a toilet cubicle at the railway station, he saw a man standing in front of him. He was convinced that the man touched his ear as if activating a hidden microphone and the voice told him that the man was going to prevent him leaving. B struck the victim's face and ran out of the toilets. Box 4 outlines an evaluation of B's subjectivity.

\section{Violent robbery vignette}

$\mathrm{C}$ committed a robbery of a newsagents when he was 19 years old. Seeing that the shop was empty, he went in and walked straight up to the counter. He opened his jacket to show that he was holding a knife and demanded that the cashier give him the money from the till. She had started placing money on the counter when a young man entered the shop. $\mathrm{C}$ grabbed the money and made for the door but the man, who had not seen the knife, grabbed him. C lashed out with the knife, causing the man to sustain a cut to his neck and a stab wound to his thigh. When interviewed, C stated that he had a heroin and cocaine addiction and he had planned to spend the proceeds of the robbery on drugs. He had taken cocaine before the offence. C's subjectivity is evaluated in Box 5 .

\section{Conclusions}

Explanatory links between psychological correlates of behaviour and the behaviour itself depend on connecting mechanisms. These mechanisms can be represented using brain-based or mind-based frames of reference. Whether or not these are different representations of the same thing (one's conclusion will depend on the philosophical perspective adopted), there is undoubtedly a distinction in the way these two representations are assessed. The day-to-day work of a mental health clinician involves obtaining accounts of the patient's experience and therefore relies on mind-based representations. The exploration of mind-based representations linked to the commission of violence should be informed by an evidence-based understanding of causal processes underlying violence. This article presents a summary of this evidence base with the intention of assisting clinicians tasked with assessing and understanding a history of violence and applying that understanding to clinical and risk management.

\section{References}

Allen JJ, Anderson CA, Bushman BJ (2018) The general aggression model. Current Opinion in Psychology, 19: 75-80.

Anderson CA, Bushman BJ (2002) Human aggression. Annual Review of Psychology, 53: 27-51

Anderson C, Hildreth JAD, Howland L (2015) Is the desire for status a fundamental human motive? A review of the empirical literature. Psychological Bulletin, 141: 574-601

Bandura A (1999) Moral disengagement in the perpetration of inhumanities. Personality and Social Psychology Review, 3: 193-209.

Banks DM, Scott BG, Weems CF (2018) Anxiety, hostile attributions, and differences in heart rate response to ambiguous situational vignettes in adolescents. Emotion, 18: 248-59.

Blader JC (2018) Disruptive mood dysregulation, and other disruptive or aggressive disorders in ADHD. In Moodiness in ADHD: A Clinician's Guide (ed B Daviss). Springer.

Blair RJR (2016) The neurobiology of impulsive aggression. Journal of Child and Adolescent Psychopharmacology, 26(1): 4-9.

Bohm R, Rusch H, Gurerk 0 (2016) What makes people go to war? Defensive intentions motivate retaliatory and preemptive intergroup aggression. Evolution and Human Behavior, 37: 29-34.

Botelho M, Goncalves RA (2016) Why do people kill? A critical review of the literature on factors associated with homicide. Aggression and Violent Behavior, 26: 9-15.

Buss AR (1978) Causes and reasons in attribution theory: a conceptual critique. Journal of Personality and Social Psychology, 36: 1311-21.

Chan SC, Raine A, Lee TMC (2010) Attentional bias towards negative affect stimuli and reactive aggression in male batterers. Psychiatry Research, 176: 246-9.

Chen C, Martinez RM, Cheng Y (2018) The developmental origins of the social brain: empathy, morality and justice. Frontiers in Psychology, 9: 2584.

Crick NR, Dodge KA (1996) Social information-processing mechanisms in reactive and proactive aggression. Child Development, 67: 993-1002.

Decety J, Cowell JM (2018) Interpersonal harm aversion as a necessary foundation for morality: a developmental neuroscience perspective. Development and Psychopathology, 30: 153-64.

Dennett D (2017) From Bacteria to Bach and Back: The Evolution of Minds. Allen Lane.

Dodge KA, Malone PS, Lansford JE, et al (2015) Hostile attributional bias and aggressive behavior in global context. Proceedings of the National Academy of Sciences of the United States of America, 112: 9310-15.

Duke AA, Smith KM, Oberleitner LMS, et al (2018) Alcohol, drugs and violence: a meta-meta-analysis. Psychology of Violence, 8: 238-49.

Falk M, Herpertz SC, Bertsch K (2015) Aggression in borderline personality disorder: a multidimensional model. Personality Disorders: Theory, Research and Treatment, 6: 278-91.

Finkel EJ, Hall AN (2018) The I Model: a metatheoretical framework for understanding aggression. Current Opinion in Psychology, 19: 125-30.

Gilbert F, Daffern M (2017) Aggressive scripts, violent fantasy and violent behavior: A conceptual clarification and review. Aggression and Violent Behavior, 36: 98-107

George DT, Grant BA (2019) Aggression in alcohol use disorder and alcohol's role in aggression. In Aggression: Clinical Features and Treatment across the Diagnostic Spectrum (eds EF Coccaro, MS McCloskey). American Psychiatric Association Publishing.

Graham K, West P, Wells S (2000) Evaluating theories of alcohol-related aggression using observation of young adults in bars. Addiction Research, 95: 847-63.

Groves CL, Anderson CA (2018) Aversive events and aggression. Current Opinion in Psychology, 19: 144-8. 
Hofmann SG (2017) Clinical Psychology: A Global Perspective. WileyBlackwell.

Howard RC (2011) The quest for excitement: a missing link between personality disorder and violence? Journal of Forensic Psychiatry and Psychology, 22: 692-705.

Huesmann LR (2016) An integrated theoretical understanding of aggression. In Aggression and Violence: A Social Psychological Perspective (ed BJ Bushman). Routledge.

Huesmann LR (2018) An integrative theoretical understanding of aggression: a brief exposition. Current Opinion in Psychology, 19: 119-24.

Igoumenou A, Harmer CJ, Yang M, et al (2017) Faces and facets: the variability of emotion recognition in psychopathy reflects its affective and antisocial features. Journal of Abnormal Psychology, 126: 1066-76.

Lamsma J, Harte JM (2015) Violence in psychosis: conceptualizing its causal relationship with risk factors. Aggression and Violent Behavior, 24: 75-82.

Lemerise EA, Arsenio WF (2000) An integrated model of emotion processes and cognition in social information processing. Child Development, 71: 107-18.

Lerner JS, Li Y, Valdesolo P, et al (2015) Emotion and decision-making. Annual Review of Psychology, 66: 799-823.

Li C, Sun Y, Yee Ho M, et al (2016) State narcissism and aggression: the mediating role of anger and hostile attribution bias. Aggressive Behavior, 42: $333-45$.

Link BG, Stueve A (1994) Psychotic symptoms and the violent/illegal behaviour of mental patients compared to community controls. In Violence and Mental Disorder: Developments in Risk Assessment (eds J Monahan, HJ Steadman). University of Chicago Press.

Mann L, Feddes AR, Leiser A, et al (2017) When is humiliation more intense? The role of audience laughter and threats to self. Frontiers in Psychology, 8: 495.

Martinelli A, Ackerman K, Bernhard A, et al (2018) Hostile attribution bias and aggression in children and adolescents: a systematic literature review on the influence of aggression subtype and gender. Aggression and Violent Behavior, 39: 25-32.

Mekawi Y, Bresin K, Hunter CD (2016) White fear, dehumanization, and low empathy: lethal combinations for shooting biases. Cultural Diversity and Ethnic Minority Psychology, 22: 322-32.
Moore C (2015) Moral disengagement. Current Opinion in Psychology, 6: 199-204.

National Collaborating Centre for Mental Health (2015) Violence and Aggression: Short-Term Management in Mental Health, Health and Community Settings. Updated Edition (NICE Guideline No. 10). British Psychological Society and Royal College of Psychiatrists.

Oxford English Dictionary (2019) OED Online. Oxford University Press (https://www.oed.com/). Accessed 5 August 2019.

Parrott DJ, Eckhardt Cl (2018) Effects of alcohol on human aggression. Current Opinion in Psychology, 19: 1-5.

Perdersen W, Copes H, Sandberg S (2016) Alcohol and violence in nightlife and party settings: a qualitative study. Drug and Alcohol Review, 35(5): 557-63. Peters RS (1960) The Concept of Motivation. Routledge.

Repple J, Pawliczek CM, Voss B, et al (2017) From provocation to aggression: the neural network. BMC Neuroscience, 18: 27.

Ridderinkhof KR (2017) Emotion in action: A predictive processing perspective and theoretical synthesis. Emotion Review, 9: 319-25.

Roberton T, Daffern M, Bucks RS (2012) Emotion regulation and aggression. Aggression and Violent Behavior, 17: 72-82.

Salum GA, Mogg K, Bradley BP, et al (2016) Association between irritability and bias in attention orienting to threat in children and adolescents. Journal of Child Psychology and Psychiatry, 58: 595-602.

Silva JA, Derecho DV, Leong GB, et al (2001) A classification of psychological factors leading to violent behaviour in posttraumatic stress disorder. Journal of Forensic Sciences, 46: 309-16.

Tremblay RE, Nagin DS, Séguin JR, et al (2004) Physical aggression during early childhood: trajectories and predictors. Pediatrics, 114: e43-50.

Vasquez EA, Wenborne L, Peers $M$, et al (2015) Any of them will do: in-group identification, out-group entitativity, and gang membership as predictors of group-based retribution. Aggressive Behavior, 41: 242-52.

Wood JL (2014) Understanding gang membership: The significance of group processes. Group Processes \& Intergroup Relations, 17: 710-29.

Wyckoff JP (2016) Aggression and emotion: anger and not general negative affect, predicts desire to aggress. Personality and Individual Differences, 101: 220-6.

Yang S, Mulvey EP (2012) Violence risk: re-defining variables from the first person-perspective. Aggression and Violent Behavior, 17: 198-207. 


\section{MCOs}

Select the single best answer for each question stem

1 In explaining human behaviour (including violence):

a the terms 'cause' and 'reason' should be seen as equivalent

b 'intention' is used to describe the objective of the violent act as anticipated by an observer

c 'rationalisation' is a retrospectively stated reason for a violent act that is, by definition, objectively illogical

d process narratives are useful in developing explanatory formulations

e the term 'function' is used to describe only factors external to the individual.

2 In the context of assessing the subjectivity of violence perpetration:

a to understand the subjectivity of violence perpetration, one should ignore the objective properties of the identified trigger

b a trigger for violence is always an external event

c the terms 'reactive' and 'instrumental' describe categorically distinct types of violence d a premeditated violent incident can include reactive elements

e trigger events for violence are, by definition, events against which the perpetrator of violence reacts.

\section{As regards intent attribution and the per-} petration of violence:

a a tendency to attribute hostile intent is associated with a reduced likelihood of aggression

b a tendency to attribute hostile intent is a characteristic feature of clinical depression

c aggression is, by definition, an action in response to the attribution of hostile intent

$d$ aggression as a reaction to the actions of another person always involves the perpetrator having attributed malign intent to that person

e fleeting paranoid reactions are a recognised feature of borderline personality disorder.

4 As regards the state of preparedness for action:

a neurobiological research supports differences in the patterns of neural activation between the state of preparedness to act and the top-down regulatory processes inhibiting action b in social information processing models, the term 'script' is used to describe the retrospective narrative account of behaviour

c increased availability of aggressive scripts reduces the risk of violence

$d$ in-group versus out-group biases tend to favour aggression towards members of the in-group

e poor social problem-solving is associated with a lower risk of aggression.

5 As regards explanatory processes for violence, which of the following is false?

a the peak prevalence of aggression is around the age of $2-3$ years

b an important mechanism for the ordinary developmental reduction in the prevalence of aggression is the capacity to implicitly adopt the perspective of others

c moral disengagement refers to the process of distancing oneself from usual moral standards in a way that inhibits aggression

$\mathrm{d}$ anger is associated with an increased likelihood of attention bias to threat-related cues

e alcohol tends to reduce the power of inhibitory influences on aggressive urges. 